Georgia State University

ScholarWorks @ Georgia State University

\title{
Laboratory Office Hours as Outreach in the Health Sciences: Better Research Skills for Better Careers
}

Todd Prusin

Georgia State University, tprusin@gsu.edu

Follow this and additional works at: https://scholarworks.gsu.edu/univ_lib_facpub

Part of the Library and Information Science Commons, and the Medical Education Commons

\section{Recommended Citation}

Prusin, T. (2012) Laboratory office hours as outreach in the health sciences: Better research skills for better careers. University Library Faculty Publications, Paper 92.

This Article is brought to you for free and open access by the Georgia State University Library at ScholarWorks @ Georgia State University. It has been accepted for inclusion in University Library Faculty Publications by an authorized administrator of ScholarWorks @ Georgia State University. For more information, please contact scholarworks@gsu.edu. 


\title{
Laboratory Office Hours as Outreach in the Health Sciences: \\ Better Research Skills for Better Careers
}

\begin{abstract}
Medical librarianship is changing in healthcare environments. Since 1996, by which time the standards that determine how hospitals acquire accreditation changed, many hospitals are acquiring accreditation without a qualified medical librarian on site. For that reason, it has become even more important that healthcare professionals, doctors, nurses and other clinicians, learn to access and evaluate quality information as an integral part of their academic training. Because of this, medical clinicians must begin their careers with strong research skills. These skills must be attained during their academic matriculation and studies in the field of librarianship have shown that departmental outreach hours are an extremely effective way to promote library services to university students, as well as faculty. Other methods, such as technology applications, are useful, but have their limitations. This paper reviews current literature on the vital importance of inperson outreach to future healthcare professionals, and illustrates these insights with a discussion of my personal experiences as a health sciences librarian at Georgia State University.
\end{abstract}

Keywords: academic libraries; outreach programs; health sciences; nursing; public health; patient safety; information literacy; embedded librarian; field librarians; library liaison; subject specialists; library best practices; user needs.

Todd Prusin

Health Sciences Librarian

Georgia State University Library

100 Decatur Street SE

Atlanta, GA 30303 
404.413.2866

tprusin@gsu.edu

\section{INTRODUCTION}

The Joint Commission on Accreditation of Healthcare Organizations (JCAHO), the governing body for hospital accreditation, now provides accreditation to hospitals without librarians. "Library services are covered in [JCAHO's] Comprehensive Accreditation Manual for Hospitals. The latest standards make no provision that the hospital should have a library or a librarian" (Paradise, 2004).

The standards in the 1989 edition of The Manual (published in 1988) included a chapter titled "Professional Library and Health Information Services." It was a four page chapter requiring that:

Whenever feasible, all professional library resources within the hospital are under the direction of a qualified medical librarian. A hospital that requires extensive library services employs at least one qualified medical librarian on a full-time basis, as well as adequate support staff. A qualified medical librarian either is an individual who holds a graduate degree in library science from a school accredited by the American Library Association and is certified by 
the Medical Library Association or has documented equivalent education, training, and/or experience (Joint Commission on Accreditation of Healthcare Organizations, 1988).

In the 1993 (published in 1992) edition the same chapter was one page and required that:

The hospital provides library and health information services that meets the informational, educational, and, when appropriate, research-related needs of the medical and hospital staffs. The staffing for library services is designed to meet the needs of the medical and hospital staffs (JCAHO, 1992).

As of 1996 The Manual made no mention of library services and currently only requires that a "hospital provides access to knowledge-based information resources" (JCAHO, 2010).

Many librarians have written about their concerns to the future of hospital librarianship.

The biggest factor placing [hospital] libraries in danger is deprofessionalization. JCAHO does not require a professional librarian to oversee the provision of information services or the library itself. It just says that a hospital must have information service available. If [hospital] management knows it can get accreditation without a degreed librarian or an actual library in place, then it has no incentive to provide either (Banick, 2005). 
"Clearly, there is a danger that, if JCAHO does not specify that a hospital should have a librarian, hospital administrators might decide that libraries and librarians are expendable" (Paradise, 2004). The motivation for hospitals to provide research support will dwindle as economic recession forces costs to be cut and tasks to be consolidated. The absence of medical librarians will place more pressure on nurses and other hospital personnel to do their own research and they will be required to conduct this research while also doing their primary jobs. If "doctors and other staff don't have the time or specific training to do their own reference work" (Banick 2005), they may find themselves in trouble as there will be little, if any, research assistance. This increased work load places more importance on the need for advanced research skills. If doctors and nurses do not have an expertise in their field, patients' safety may be at risk. "The absence of search techniques suggested that practitioners might not be receiving the best evidence" (Hider, 2009).

An unfortunate example of a practitioner not accessing the best evidence took place at Johns Hopkins University in 2001, when a twenty-four year old woman participating in a clinical study on asthma was given a drug which caused irreversible lung damage, and she died (Altman, 2001a, 2001b). After the tragedy, "medical librarians looked at the case [and] it became apparent that the drug had a history of causing lung damage (Paradise, 2004)."

Medical librarians around the country immediately searched various sources and by using just online resources discovered disturbing information on problems associated with [said] drug. 
For instance, a quick search of [various databases] showed many citations identifying relevant articles [and] yielded relevant citations in the references sections. These citations are available online, but in other resources than those the Johns Hopkins physician researcher relied upon (Perkins, 2001).

Had a search, or at least a better search, on the drug in question been performed, articles published as far back as the 1950's would have discouraged its use. Many librarians came to the same conclusion that "this kind of tragedy offers a terrible lesson in the importance of using professional searchers and medical librarians in critical searching situations" (Perkins, 2001). It was generally agreed upon that "other factors may have contributed to the tragedy, but clearly in this case, the lack of a librarian's search was an essential factor" (Paradise, 2004).

I served as a hospital librarian for 2 years and developed an understanding of the research needs of practicing clinicians. I worked with doctors and nurses who did not have time to do research. I also met others who did not know how to use databases or generate valid citations for their query. Clinicians would just tell me what information they needed and I would prepare a list of citations and abstracts. They didn't know what databases I used or from where the articles came. Considering that doctors and nurses are busy practicing medicine, their careers may have taken them past the point of needing to rely on strong research skills. Now however, in the changing regulatory environment and with patient safety at risk, the need for health services professionals to possess competent information 
search skills is arguably becoming more important. Individuals without proper training in database searches are more likely to perform unsuccessful searches. As such, health care professionals -- especially those planning on careers in hospitals -

- must develop the skills necessary to use library resources throughout their academic training.

\section{THE ARGUMENT FOR ACADEMIC OUTREACH}

Most librarians will agree on the importance of outreach. If our patrons are unaware of the information we have, our resources go unused and our efforts are wasted. With this in mind, academic librarians spend a lot of time, money and effort to promote reference and consultation services to patrons.

Limits of the Reference Desk. Traditionally, academic libraries have reference desks and librarians who are available to assist patrons. Any reference librarian can readily tell an anecdote about patrons who have demonstrated opaque research goals or a limited understanding of the research process - but time limitations and the public nature of the reference desk are not conducive to lengthy interaction.

Other limits of the reference desk stem from student discomfort with asking questions. One study suggests that students equate consulting a librarian "to a public confession of their inadequacy" (Lee, et al. 2004). While such a characterization may seem harsh, some "students are often hesitant to demonstrate their lack of knowledge and their inability to find information independently" (Lee, et al. 2004). It is important to acknowledge the feelings of 
such students considering these students are among those who are not coming to the library for help. Some alternative outreach activity may allow the student to:

Avoid this perceived admission of ignorance if the [librarian] is in a place where students normally feel comfortable. For instance, a lab, which students may think of more as 'theirs,' could be one place to offer assistance. This idea of bringing public services to clients, especially within faculties and departments is just one of many strategies which may reach clients unwilling or unable to visit a library's main information desk (Lee, et al. 2004).

Some libraries have set up "ask me booths" in heavily trafficked areas on campus, but these portable reference desks do not targets students from specific disciplines or utilizes the subject strengths of the librarians.

Limits of Library Outreach Hours. Subject-specialist outreach hours provide the opportunity for librarian interaction with students in specific disciplines. To promote this service, librarians' phone numbers, e-mail addresses and office locations are freely disseminated. Unfortunately, this neither guarantees nor necessarily even encourages patron interaction. Students may feel uncomfortable within the formality of librarian offices or feel their consultation is an imposition. They often move quickly from class to class or place to place and may not budget the time necessary to visit with their liaison librarian. One study even went so far as to suggest that students equate consulting a librarian "to a public confession of their inadequacy" (Lee, et al. 2004). While such a characterization may seem 
harsh, some "students are often hesitant to demonstrate their lack of knowledge and their inability to find information independently" (Lee, et al. 2004).

Limits of technology. Over the last 20 years, technological advances have influenced the direction of outreach activities. In an expanding professional role, librarians lead the way for those who are less technologically savvy, and try to keep up with those who excel technologically. Using these technologies, libraries provide access for all types of patrons, even those who do not physically enter the library.

Even with all this technology, the abilities of younger students to find appropriate information have been called into question. Mark Bauerlein's The Dumbest Generation (2008) sums up the situation by claiming that, with the information superhighway and a world of knowledge available to them, the younger generation today may be less informed and less literate than any that has preceded it. As the Internet continues to grow, the ability for users to organically develop successful research skills may diminish and the need for effective guidance will be greater than ever.

This assertion may be debatable, but regardless, the working relationship between librarians and students is a traditional part of academic study. Even with the introduction of the Internet, social software, online full-text access and virtual reference, students still need help finding information. In fact, all this technological advancement may simply have muddied the research waters.

In 2006, Educational Testing Service (the developer of the SAT) released the findings of a survey of high school and college students and their digital research skills. The impetus for the study came from 
librarians and teachers who noticed that, for all their adroitness with technology, students don't seek, find, and manage information very well. They don't always cite pertinent sources and compose organized responses to complete class assignments. They're comfortable with the tools, but indiscriminate in their applications (Bauerlein 2008).

In short, digital forms of communication are worthless if the patron does not engage; students may be most comfortable simply speaking with a librarian faceto-face.

To facilitate this interaction, the librarian must be "willing to leave the library to go to their patrons' offices or classrooms" (Scherrer, 2004). Additionally, "librarians need to reach outward to become an integral part of the routine interactions of faculty and students" (Ramsay \& Kinnie, 2006). "By visiting clients in person, we are telling them: 1 . they are a priority and 2 . this is what I can do for you" (Peros, 2005).

This approach has been successfully adopted. Scherrer (2004) found that in recent years librarians have:

Universally reported that they were leaving the library and meeting patrons where they work, do research, or teach. In the past, we expected patrons to come to us; now we have to take the initiative and go to them. We have to anticipate their information needs. For librarians, this includes leaving the immediate grounds where the library is located and visiting [patrons]. 
Outreach hours provide a forum removed from social networking and other popular forms of technology. It is not until the librarian and patron are face-to-face or side-by-side, that the librarian able to guide the patron on the Internet.

\section{LABORATORY OUTREACH HOURS}

One way to optimize student comfort and face-to-face interaction, while still utilizing technology, is to hold outreach office hours in departmental computer labs. This is where students congregate for both scholarly and social reasons. In a computer lab, students are likely already engaged in the pursuit of some kind of information. A librarian's participation becomes a natural part of the on-going activity. Librarians have exerted this type of effort for years and most designs are similar with "the librarian available for individual consultation within the physical space of the academic department, offering services to departmental faculty, graduate students, and undergraduate students" (Avery et al., 2008).

The value of outreach hours has been discussed in the literature. In addition to the services provided by outreach hours,

There have been several ancillary benefits to the library and its users.

By moving closer to the physical learning communities of the disciplines, librarians were more likely to be included in [their departments]. The librarian, therefore, can become more a part of the faculty community because $s /$ he is more visible and approachable. Getting to know the faculty, graduate and undergraduate students may provide better information for collection improvement, advance notice of courses in the planning stages, and information on difficulties 
clients have with using the library's resources that they might not articulate in the library. The opportunity for improved communication also enhanced the library's marketing efforts, leading to new instruction classes being booked, and greater awareness of library resources (Lee et al., 2004).

\section{CASE STUDY}

Georgia State University is located in downtown Atlanta and is a major research university with an enrollment of over 30,000 undergraduate and graduate students in six colleges. The Lewis School of Nursing has approximately 500 students in the baccalaureate, masters and PhD programs. The faculty includes approximately 40 full-time and 20 part-time nurse-educators. The Institute of Public Health has 120 masters students and 16 faculty members. Both departments have their own computer labs. Students and faculty utilize the labs for classes, testing, schoolwork, research and a place to check their e-mail. Due to heavy student traffic, a librarian presence has the potential to generate consultations.

The Georgia State University library houses over 1.5 million volumes, including 28,000 electronic journals, 2,800 periodicals and newspaper titles, nearly 8,000 active serials, and is a Federal Document Depository with more than 820,000 government documents. There are over 20 liaison librarians, or subject specialists, assigned to various university colleges and departments. I am the health sciences liaison assigned to the Institute of Public Health and the Lewis School of Nursing. All Georgia State University librarians log their consultations as a means of assessing 
library performance. Methods of contact include in-person visits, e-mail, telephone calls or Instant Messaging.

In 2005, I joined the library faculty at Georgia State University where I now serve as the subject specialist liaison for the School of Nursing and the School of Public Health. The contrast between the functions of a hospital librarian and academic librarian is significant. Hospital librarians generally just provide research service. In the academic library, the librarian's job is to teach students how to find information. As part of my responsibilities, I now teach students how to do mediated searches in various databases and how to determine if various resources are available in the library collection, either in print or online.

Developing the plan. As a new academic librarian, I was strongly motivated to prepare the Georgia State University health sciences students for careers in hospitals and other settings. I believed that my experience as a hospital librarian gives me a strong grasp of what the health sciences student needs from an academic librarian. "The most commonly cited success factor for outreach projects was understanding customer need. Other factors include networking \& building relationships, collaboration with faculty and academic department, and knowing your audience" (Fama et al., 2005).

My supervisor in the Library's department of liaison services encouraged the idea of remote location research support as means of interacting with students and faculty. With the help of department faculty, I researched the times when students would most likely be in the labs. We reviewed the spring 2007 semester class schedule and determined the days on which most students would be on campus 
and when they would be between classes. My main goal was to determine the best time to offer such a research services.

Upon exiting a communication restrictive environment, such as class, most people will re-connect via a portable device such as an iPhone or Blackberry or, if available, the Internet. The PC lab provides this access as well as allowing students conduct school work and research. I reasoned that if I positioned myself in this environment, students would most likely interact with me and eventually utilize my health science subject specialty.

Implementation. In January 2007, I established outreach hours in these computer labs. I was in the lab 2 hours a day on Thursday and Friday mornings, my schedule was posted on my website and on the lab walls and I announced them at new student orientation and in classroom visits. In the labs, I take up residency at a computer, wear a name tag and sit behind a "librarian" sign. Students know I am there and view me in a collegial way. During my consultations I instruct the student how to do the work by letting them "drive" the computer mouse.

An example of a popular lesson is when I teach patrons how to create accounts in databases such as PubMed or CINAHL. Here they can organize their searches and save citations. This lesson does not find its way into a limited formal library class orientation.

I often interact with students who have trouble understanding how our catalog translates to the physical library. Since outreach hours take place away from the library, I am unable to simply turn and walk the patron to their goal. For example if the article is available online, the consultation may not require an 
understanding of our physical library. When the consultation requires the student to enter our library, the content of the reference transaction changes and other lessons must be administered. During outreach hours I am not near our stacks and potentially a student has not been in our library. To tell them where an item is may not translate. When this happens I walk them over to the library and show them our full text resources. The current student body is often unaware that "full text" includes on-the-shelf print sources, and after being shown what was available in the library, they will share their experience with others.

Results of laboratory interaction. At first, student participation was slow. In the first month, I had only four laboratory consultations with students. Then, both students and faculty began to utilize my services. Many reference transactions were a direct result of simply being seen. Patrons slowly started to visit the labs when they knew I would be there, and often I would help multiple patrons at once. Many students with whom I had face-to-face interactions during outreach hours would later email me with follow up questions.

I found myself answering questions of varying degrees of difficulty. Initially, these questions often focused on the navigational path to our online catalog and databases where book titles and/or article citations are found. With the understanding of these basic lessons, patrons became more information literate and the research questions became more complicated. The length of consultations varied from five minutes to an hour and forty minutes. Since I was not engaged in other activities, as I would have been in my office or on the reference desk, I could devote almost as much time as necessary to each student. 
Now, prior to each semester I reconvene with faculty and change my outreach hours times to best accommodate the new class schedule. Two hours per week has proven fruitful and is also the standard amount spent for other Georgia State University librarians. After holding outreach hours for four years, I have seen the number of my student and faculty consultations increase as much as $400 \%$.

\section{(Table 1: Outreach hours consultations chart)}

Other benefits are inherent in the propinquity between the librarian and faculty. By collaborating with faculty on my initial plan, they themselves also became aware of my outreach activities. I established a presence in my departments. Faculty reaction has been very positive and I believe my contribution is to student performance is appreciated.

I have frequent chats with the nursing professor whose office door is directly across from my terminal in the computer lab. These chats led to more substantive interactions and her decision to get more involved with the library's nursing collection, providing valuable assistance with a large weeding project. My frequent presence in the nursing and public health departments helped me establish relationships with faculty, and these relationships often led to formal classes for bibliographic instruction and library orientation. Most of the classes I taught have been for professors who see me in and around their departments during my outreach hours.

Most recently, another nursing professor suggested I change my outreach hours to best serve the schedules of the summer semester students. This request was entirely the result of previous efforts to establish myself within the department. 
Compared to other liaison librarians, who have trouble getting their departments to respond to their efforts, this was a very pleasant surprise and speaks to the level of success I have achieved.

My initiatives were designed to increase my visibility and strengthen connections with the nursing and public health communities. The simple nature of my increased presence suggested that I would become more familiar to both students and faculty and the demand for my services would increase. As has been reported, the "forging of stronger librarian/faculty relationships often lead to great acceptance as a professional colleague, something that cannot be discounted in evaluating the effectiveness of such office hours" (Avery et al., 2008).

\section{CONCLUSION}

It is increasingly likely that University students going into the field of health sciences will need to be prepared to do their own research on the work site. With patient safety on the line, the importance of teaching these students advanced search strategies cannot be overstated. There is no reason that future generations of doctors, nurses and other health professionals should lack the skills necessary to seek out essential information.

Opportunities for students and librarian interaction can be limited due to the challenges of student schedules, students' fears and biases or the limitations of social technology. Library outreach hours circumvent many of these limitations, allowing students to more conveniently utilize library resources. 
My experience demonstrates how a university library can provide a better foundation for research and information literacy to health science students and faculty. The simple design and implementation of my initiative should encourage subject-specialist librarians elsewhere to consider a similar endeavor. 


\section{BIBLIOGRAPHY}

Altman, L. K. (2001, June 15). Volunteer in asthma study dies after inhaling drug. New York Times (1923-Current file), p. A16.

Altman, L. K. (2001, July 3). F.D.A. faults Johns Hopkins over process in fatal study. New York Times (1923-Current file), p. A12.

American Psychological Association. (2001). Publication manual of the American Psychological Association. Washington, DC: American Psychological Association.

Avery, S., Hahn, J., \& Zilic, M. (2008). Beyond consultation: a new model for librarian's office hours. Public Services Quarterly, 4(3), 187-206.

Banick, C. (2005). RX for medical libraries. Library Journal, 130(19), 32-34.

Bauerlein, M. (2008). The dumbest generation: how the digital age stupefies young Americans and jeopardizes our future (or, don't trust anyone under 30). New York, NY: Jeremy P. Tarcher/Penguin.

Fama, J., Berryman, D., Harger, N., Julian, P., Peterson, N., Spinner, M., et al. (2005). Inside outreach: a challenge for health sciences librarians. Journal of the Medical Library Association, 93(3), 327-337.

Hider, P. N., Griffin, G., Walker, M., \& Coughlan, E. (2009). The informationseeking behavior of clinical staff in a large health care organization. Journal of the Medical Library Association, 97(1), 46-49.

Joint Commission on Accreditation of Healthcare, O. (1988). Accreditation manual for hospitals. Chicago, IL: Joint Commission on Accreditation of Healthcare Organizations.

Joint Commission on Accreditation of Healthcare, O. (1992). Accreditation manual for hospitals: volume 1, standards. Chicago, IL: Joint Commission on Accreditation of Healthcare Organizations.

Joint Commission on Accreditation of Healthcare, O. (2010). Comprehensive accreditation manual for hospitals. Oakbrook Terrace, IL: Joint Commission on Accreditation of Healthcare Organizations.

Lee, J., Hayden, K., \& MacMillan, D. (2004). "I wouldn't have asked for help if I had to go to the library": reference services on site. Issues in Science and Technology Librarianship, 41. 
Paradise, A. (2004). Why the Joint Commission on Accreditation of Healthcare Organizations should add new regulations regarding libraries. Journal of the Medical Library Association, 92(2), 166-168.

Perkins, E. (2001). Johns Hopkins tragedy. Information Today, 18(8), 51.

Peros, J. (2005). Face time. Information Outlook, 9(12), 25-27. 